\title{
Environmental stability affects phenotypic evolution in a globally distributed marine picoplankton
}

\author{
C-Elisa Schaum ${ }^{1,2}$, Björn Rost ${ }^{3}$ and Sinéad Collins ${ }^{1}$ \\ ${ }^{1}$ Ashworth Laboratories, Institute of Evolutionary Biology, University of Edinburgh, Edinburgh, UK; \\ ${ }^{2}$ Biosciences, Environment and Sustainability Institute, University of Exeter, Penryn, UK and ${ }^{3}$ Alfred Wegener \\ Institute, Helmholtz Centre for Polar and Marine Research, Marine Biogeosciences, Bremerhaven, Germany
}

\begin{abstract}
Marine phytoplankton can evolve rapidly when confronted with aspects of climate change because of their large population sizes and fast generation times. Despite this, the importance of environment fluctuations, a key feature of climate change, has received little attention-selection experiments with marine phytoplankton are usually carried out in stable environments and use single or few representatives of a species, genus or functional group. Here we investigate whether and by how much environmental fluctuations contribute to changes in ecologically important phytoplankton traits such as $\mathrm{C}: \mathrm{N}$ ratios and cell size, and test the variability of changes in these traits within the globally distributed species Ostreococcus. We have evolved 16 physiologically distinct lineages of Ostreococcus at stable high $\mathrm{CO}_{2}\left(1031 \pm 87 \mu \mathrm{atm} \mathrm{CO}_{2}, \mathrm{SH}\right)$ and fluctuating high $\mathrm{CO}_{2}(1012 \pm 244 \mu \mathrm{atm}$ $\mathrm{CO}_{2}, \mathrm{FH}$ ) for 400 generations. We find that although both fluctuation and high $\mathrm{CO}_{2}$ drive evolution, $\mathrm{FH}-$ evolved lineages are smaller, have reduced $\mathrm{C}: \mathrm{N}$ ratios and respond more strongly to further increases in $\mathrm{CO}_{2}$ than do SH-evolved lineages. This indicates that environmental fluctuations are an important factor to consider when predicting how the characteristics of future phytoplankton populations will have an impact on biogeochemical cycles and higher trophic levels in marine food webs.

The ISME Journal (2016) 10, 75-84; doi:10.1038/ismej.2015.102; published online 30 June 2015
\end{abstract}

\section{Introduction}

The function of marine ecosystems hinges on their smallest primary producers. Marine phytoplankton are responsible for roughly $50 \%$ of global primary production (Falkowski et al., 1998), are major drivers of the carbon pump (Beardall and Raven, 2004) and form the base of marine food webs (Rossoll et al., 2012; Thomsen et al., 2013). Marine phytoplankton with large population sizes and short generation times will have ample scope for evolution in a changing ocean (Collins, 2011), where $\mathrm{CO}_{2}$ levels are predicted to have doubled by the end of the century (IPCC report, 2007) and to become less stable (Egleston et al., 2010; Flynn et al., 2012). Thus, phytoplankton are and will be evolving in unstable $\mathrm{CO}_{2}$ environments. Natural fluctuations in $\mathrm{CO}_{2}$ can range from diurnal changes to annual fluctuations and changes on geological timescales, for example, due to microbial activity, severe weather and seasonal vertical mixing (Joint et al., 2011; Gilbert et al., 2008; Li et al., 2009). We have previously shown that average annual fluctuations in $\mathrm{CO}_{2}$ at the

Correspondence: C-E Schaum, Biosciences, Environment and Sustainability Institute, University of Exeter, Penryn Campus, Penryn, Cornwall, TR10 9EZ, UK.

E-mail: c.l.schaum@exeter.ac.uk

Received 27 February 2015; revised 21 May 2015; accepted 26 May 2015; published online 30 June 2015 sampling location affect the growth responses of marine picoplankton to short-term increases in $\mathrm{CO}_{2}$ (Schaum et al., 2013).

As buffering capacity decreases at lower $\mathrm{pH}$ values, any changes in dissolved $\mathrm{CO}_{2}$ are expected to become more pronounced and less predictable in the future (Egleston et al., 2010; Flynn et al., 2012), making it necessary for phytoplankton to not only evolve mechanisms to deal with $\mathrm{CO}_{2}$ levels that are on average higher than today's but also to cope with larger and more frequent deviations from that average. It has not been tested empirically whether fluctuations modulate responses to further environmental changes in marine phytoplankton, although theory and experiments on other model organisms such as Escherichia coli suggests that it should (Ghalambor et al., 2007; Draghi and Whitlock, 2012; Chevin et al., 2013; Karve et al., 2014). This is particularly important, as even under optimistic scenarios, $\mathrm{CO}_{2}$ levels in the ocean are going to increase long after the 2100 cutoff applied to most climate models (IPCC report, 2007). Yet, despite the likely influence of environmental variability on evolution, selection experiments that aim to characterize phenotypes of marine phytoplankton in a changing ocean are usually carried out in stable environments (for example, Lohbeck et al., 2012; Crawfurd et al., 2011; Tatters et al., 2013; Schlüter et al., 2014).

Most previous studies have used few representatives of a species (or, where species are cryptic, 
species complex), with no test of whether genotypically or physiologically distinct lineages of the same species differ in the phenotypes they evolve in response to elevated $\mathrm{CO}_{2}$ levels. However, this information is crucial to make predictions about how structures of phytoplankton communities and their function in the ecosystem will be affected by increased $\mathrm{CO}_{2}$ levels or climate change in a broader sense. We need two main pieces of information: who will be present in future phytoplankton communities and what they will be doing. The evolution of lineage growth rates in response to environmental change informs our predictions of how frequencies of lineages within a population are expected to change (Schaum and Collins, 2014), and thus who is likely to be there. The evolution of other aspects of the phenotype, such as size and cellular stoichiometry, allow us to understand what they will be doing and how this will affect higher trophic levels and nutrient cycling. Often, phenotypic characteristics of marine microbial communities to climate change are examined through observation and short-term experiments; however, recent years have seen an increase in studies showing that evolutionary processes need to be considered when predicting effects of climate change on marine microbial communities and the expected phenotypes (see Collins et al., 2013 for a review). In stable environments, these include decreased cell size and a partial restoration of the calcification process in the coccolithophore Emiliania huxleyi (Lohbeck et al., 2012; Schlüter et al., 2014) and lowered C:N ratios in diatoms (Crawfurd et al., 2011). However, it is not known how environmental fluctuations affect phenotypic evolution.

The goal of this study is to measure whether evolving in fluctuating high $\mathrm{CO}_{2}(1012 \pm 244 \mu \mathrm{atm}$ $\left.\mathrm{CO}_{2}, \mathrm{FH}\right)$ versus stable high $\mathrm{CO}_{2}(1031 \pm 87 \mu$ atm $\mathrm{CO}_{2}, \mathrm{SH}$ ) results in differences in the evolution of key characteristics of a marine phytoplankton. Using 16 genetically distinct lineages of the species complex Ostreococcus (Courties et al., 1994; Subirana et al., 2013) from different habitat types (for example, lineages from coasts and the open ocean, surface waters and near the deep chlorophyll maximum), we can estimate whether trait evolution in the face of elevated $\mathrm{CO}_{2}$ is conserved within a species or genus (Schaum et al., 2013; Zhang et al., 2014). As part of the phenotypic characterization, we investigate how responsive lineages evolved in the $\mathrm{SH}$ and $\mathrm{FH} \quad \mathrm{CO}_{2}$ environments are to further increases in $\mathrm{CO}_{2}$, that is, how well they are able to adjust their growth rates in response to further $\mathrm{CO}_{2}$ enrichment. The rationale for this is that the ability to adjust growth rates in response to environmental fluctuations is likely an important trait in marine picoplankton when marine environments become more variable. It is not feasible to measure all possible phenotypic traits; hence, here we focus on key traits that determine the role of phytoplankton in biogeochemical cycles, food webs or both.
For example, the ratio of oxygen evolution and consumption, combined with size and C:N ratios, data can inform future studies or models on carbon export to the deeper ocean. In addition, changes in size and elemental composition can affect the quality of phytoplankton as a food source for grazers so that changes in the elemental composition of phytoplankton can affect grazer population size and life history (Rossoll et al., 2012; Thomsen et al., 2013).

\section{Materials and methods}

\section{Cultures and experimental setup}

We used 16 lineages of Ostreococcus from 9 habitat types (see Schaum et al., 2013 and Supplementary Table S1). Lineages were made clonal by dilution at the beginning of the experiment (Schaum and Collins, 2014). Three biological replicates of each lineage were grown in each of the four $\mathrm{CO}_{2}$ selection environments: stable ambient (SA $444 \pm 43 \mu \mathrm{atm}$ $\mathrm{CO}_{2}$ ), fluctuating ambient (FA $490 \pm 97 \mu \mathrm{atm} \mathrm{CO}_{2}$ ), $\mathrm{SH}\left(1031 \pm 87 \mu \mathrm{atm} \mathrm{CO}_{2}\right)$ and $\mathrm{FH}(1012 \pm 244 \mu \mathrm{atm}$ $\mathrm{CO}_{2}$ ). This is a total of 192 populations in the experiment (16 lineages $\times 3$ biological replicates $\times 4$ selection environments; see Figure 1 for experimental setup). Temperature $\left(18^{\circ} \mathrm{C}\right)$, salinity (31) and light intensity $(160 \mu \mathrm{E})$ were kept stable, while $\mathrm{pCO}_{2}$ was varied. In the fluctuating treatments, $\mathrm{pCO}_{2}$ was set to change every 7 days (in the SA environment, Ostreococcus divide about once a day), to a random value between 430 and $630 \mu \mathrm{atm} \mathrm{CO}_{2}$ for $\mathrm{FA}$, and 700 and $1300 \mu \mathrm{atm} \mathrm{CO}_{2}$ for $\mathrm{FH}$ environments. Samples were maintained in a semi-continuous batch culture with a transfer approximately every seven generations (see also Schaum and Collins, 2014).

Before evolution in any of the selection environments (t0) and also following 100 (t100) and 400 (t400) generations of evolution in the selection environments, populations were grown at 430 and $1000 \mu \mathrm{atm} \mathrm{CO}_{2}$ for 7-14 generations and then assayed for the investigated phenotypic traits (see Supplementary Figure S1B for FH and SH at 430 uatm $\mathrm{CO}_{2}$ ). At t600, samples from all selection environments were assayed for growth rates and other phenotypic traits at $2000 \mu \mathrm{atm} \mathrm{CO}_{2}$ (see Figure 1). To account for the additional generations passed, growth rates, size and chlorophyll content were also re-measured for all populations evolved in SA, FA, $\mathrm{SH}$ and $\mathrm{FH}$.

As this study focuses on trait evolution, we report three response types for lineages after they have evolved in their respective selection environments: ambient, plastic and evolved responses. Here the ambient responses are phenotypic traits of lineages evolved at SA or FA that have been measured at $430 \mu \mathrm{atm} \mathrm{CO}_{2}$. The respective trait values function as a reference to which the plastic and evolved responses are compared. Plastic responses are changes in phenotype that do not require any 
Selection environment $\left[\mu \mathrm{atm} \mathrm{CO}_{2}\right]$

FA $\quad$ SH $\quad F H$
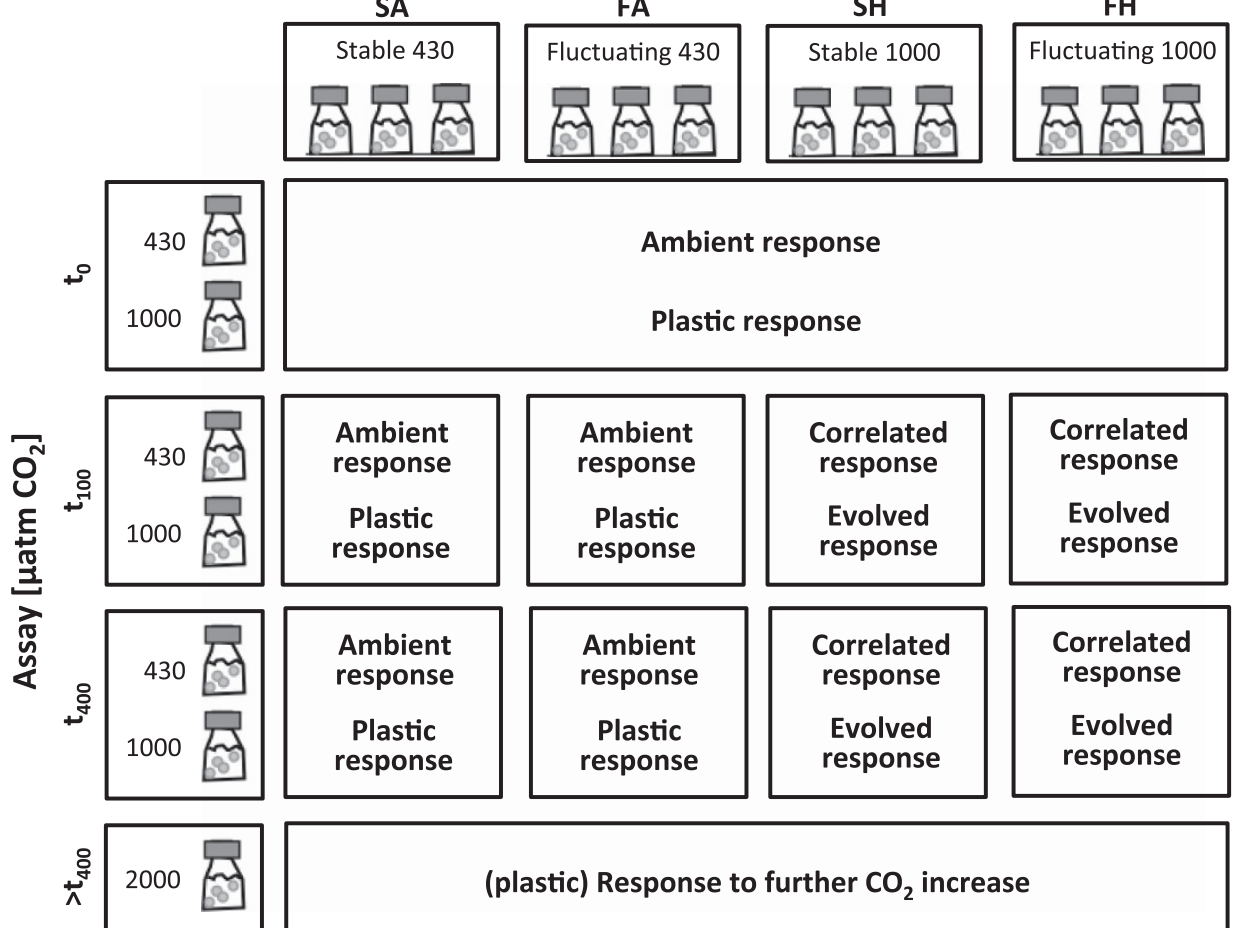

Figure 1 Experimental setup: 3 biological replicates of 16 lineages of the species complex Ostreococcus were evolved in 4 selection environments. These were SA ( $\left.444 \pm 43 \mu \mathrm{atm} \mathrm{CO}_{2}\right)$, FA $\left(490 \pm 97 \mu \mathrm{atm} \mathrm{CO}_{2}\right), \mathrm{SH}\left(1031 \pm 87 \mu \mathrm{atm} \mathrm{CO}_{2}\right)$ and FH $\left(1012 \pm 244 \mu \mathrm{atm} \mathrm{CO}_{2}\right)$. At the beginning of the experiment (t0), as well as at $100(\mathrm{t} 100)$ and $400(\mathrm{t} 400)$ generations into the experiment, phenotypes of all samples were assayed at both 430 and $1000 \mu$ atm $\mathrm{CO}_{2}$. We refer to SA- and FA-evolved phenotypes measured at 430 and $1000 \mu$ atm $\mathrm{CO}_{2}$ as ambient and plastic responses, respectively. We refer to phenotypes of $\mathrm{FH}$ - and $\mathrm{SH}$-evolved lineages measured in the $1000 \mu \mathrm{\mu tm} \mathrm{CO}_{2}$ assay as evolved responses. FH- and SH-evolved lineages assayed at $430 \mu$ atm $\mathrm{CO}_{2}$ are referred to as correlated responses (see Supplementary Figure S1). Shortly after t400, we also assayed all samples at $2000 \mu \mathrm{atm} \mathrm{CO}_{2}$ and call this a response to further $\mathrm{CO}_{2}$ increase. We discuss all but the correlated responses in detail in the main text. For correlated responses, see Supplementary Information.

underlying change in genotype (West-Eberhard, 2003). Plastic responses here are the short-term responses to elevated $\mathrm{CO}_{2}$ levels. To measure the phenotype of the plastic response, lineages evolved at SA or FA are measured at $1000 \mu \mathrm{atm} \mathrm{CO}_{2}$. These lineages have not evolved in high- $\mathrm{CO}_{2}$ environments; hence, their phenotypes at high $\mathrm{CO}_{2}$ are a measure of the phenotypic change that occurs in the absence of genetic evolution in response to long-term growth in a high- $\mathrm{CO}_{2}$ environment. It is noteworthy that this is sometimes also called an acclimation response in other studies. Here we reserve the word 'acclimation' for the period where we allowed populations to acclimate to the assay environment before measuring traits. As our lineages were founded from clonal populations, we argue that any change in average population phenotype observed within 14 generations is unlikely to have arisen through de novo mutation or genotype sorting. We also show that the response is reversible by transferring the samples back to $430 \mu \mathrm{atm}$ after exposure to elevated $\mathrm{CO}_{2}$ (Supplementary Figure S1A). Likewise, the response of SA-, FA-, SH- and FH-evolved lineages to 2000 $\mu$ atm $\mathrm{CO}_{2}$ is a plastic response. Evolved responses are changes in phenotype that are due to changes in the genotypic makeup of the population over time. Evolved traits are usually described as changes in phenotype of the evolved populations growing in their selective environment (here, $\mathrm{FH}$ or $\mathrm{SH}$ growing in high $\mathrm{CO}_{2}$ ) relative to the phenotype of an ancestral or control population grown in the same environment (here, SA and FA evolved in ambient $\mathrm{CO}_{2}$ environments but were measured in high $\mathrm{CO}_{2}$ ). We refer to phenotypic traits measured in $\mathrm{SH}-$ and $\mathrm{FH}-$ evolved populations at $1000 \mu \mathrm{atm} \mathrm{CO}_{2}$ as evolved responses and describe the correlated responses ( $\mathrm{SH}$ and $\mathrm{FH}$ at $430 \mu \mathrm{atm} \mathrm{CO}_{2}$ ) in the Supplementary Information (Supplementary Figure S1B).

The SA environment controlled for any changes in phenotype that might occur due to evolution in a lab environment. The FA environment selected for the maintenance and/or evolution of plasticity (that is, the ability to produce a plastic response) to fluctuations in $\mathrm{pCO}_{2}$ alone. The $\mathrm{SH}$ environment selected for growth at high $\mathrm{CO}_{2}$ alone, whereas the $\mathrm{FH}$ environment selected for the maintenance and/or evolution of plastic responses due to high as well as fluctuating $\mathrm{CO}_{2}$ environment. For detailed carbonate chemistry tables for the different selection environments, please refer to Supplementary Table S2. 
Physiological responses

Samples were acclimated to the appropriate $\mathrm{CO}_{2}$ level as described above before the physiological assays. $\mathrm{CO}_{2}$ levels of 430,1000 or $2000 \mu$ atm $\mathrm{CO}_{2}$ were established through bubbling artificial seawater in the respective $\mathrm{CO}_{2}$ incubator for at least $24 \mathrm{~h}$ before any cultures were added. Seawater DIC (dissolved inorganic carbon), alkalinity and $\mathrm{pH}$ were measured regularly as described in the Supplementary Information.

Growth rates, oxygen evolution and consumption rates. Growth rates were calculated from the intact, chlorophyll a-positive event counts within an Ostreococcus-specific gate of forward and side scatter on a FACS CANTO (BD Biosciences, Oxford, UK; see Supplementary Figure S2). Oxygen evolution and consumption rates were measured using a Clarktype oxygen electrode under conditions resembling those in the respective incubators (see Supplementary Methods for details).

Cellular stoichiometry. Particular organic carbon and nitrogen samples were taken for eight lineages per selection environment, using three technical replicates of each of three biological replicates. Samples were filtered onto pre-combusted $(12 \mathrm{~h}$, $500{ }^{\circ} \mathrm{C}$ ) $\mathrm{GF} / \mathrm{F}$ filters (1.2 mm; Whatman, GE Healthcare Life Sciences, Cardiff, UK) and stored in pre-combusted $\left(500^{\circ} \mathrm{C}\right)$ petri dishes. Filters were wrapped in tin foil and particular organic carbon and nitrogen were then measured using an Elementar Vario EL mass spectrometer (Elementar Analysensysteme GmbH, Hanau, Germany).

Cell size, chlorophyll a content and Nile Red fluorescence. Chlorophyll a content, lipid content and relative cell size were determined using a FACS CANTO (for general protocols, see (Marie et al., 2005; Petersen et al., 2012)). The red fluorescence channel was used as a proxy for total chlorophyll a content and was cross-calibrated using chlorophyll a calibration beads as standards (Bangs Laboratories, Inc., Fishers, IN, USA), as well as chlorophyll a extraction (Holm-Hansen and Riemann, 1978). The same channel was used to determine polar lipids after a Nile Red stain (la Jara de et al., 2003; Guzmán et al., 2009). Cell size was inferred from the FSC (forward scatter) and comparison with calibration beads and coulter counter measurements. Owing to the nature of flow cytometry measurements, trait values retrieved from FACS CANTO measurements are approximate (Marie et al., 2005; Petersen et al., 2012), but relative changes between samples are highly informative for comparisons of strains and selection lines.

Statistics and graphical representation

Data were analysed in the $\mathrm{R}$ environment, using mixed models within the 'nlme' and 'lme4' packages and models built based on (Pinheiro and Bates, 2000), to control for temporal effects of $\mathrm{CO}_{2}$ in assay and selection environments, and to account for the same clonal lineages being used across treatments. Owing to the multiple comparisons performed in the omnibus analysis of variance (ANOVA) detecting changes between fluctuating and stable environments across all traits, selection regimes and lineages, $P$-values were adjusted through a HolmBonferroni approach before Tukey's honest significant difference post-hoc tests performed only on $P$-values $<0.05$, that is, all post-hoc results presented throughout are already corrected for multiple comparisons. Smaller ANOVA analyses were performed to gain more detailed information, for example, on the effect of environmental stability on specific traits or groups of lineages. The number of biological replicates per lineages was three. For graphic representation, means and s.e. per lineage, as well as per $\mathrm{CO}_{2}$ treatment, were calculated within the 'ggplot2' and 'plotrix' package. See Supplementary Information for details.

\section{Results and Discussion}

\section{Fluctuating and stable $\mathrm{CO}_{2}$ select for drastically different phenotypes}

The plastic responses of the marine picoplankton Ostreococcus to elevated $\mathrm{CO}_{2}$ before the evolution experiment have been described in Schaum et al. (2013), and in line with this we find elevated oxygen evolution and respiration rates, as well as an increase in cell size and $\mathrm{C}: \mathrm{N}$ ratio in lineages exposed to 1000 uatm $\mathrm{CO}_{2}$ at t0 (before evolution) and in SA- and FA-evolved populations (at t400) assayed at $1000 \mu$ atm $\mathrm{CO}_{2}$. Notably, phenotypes characteristic of the plastic response to elevated $\mathrm{CO}_{2}$ are not maintained when populations are allowed enough time to evolve in high- $\mathrm{CO}_{2}$ environments (Figure 2, ANOVA all traits, selection environment $\times$ assay environment $\mathrm{F}_{3,124}=9.69, P<0.05$ ) and begin to reverse after 75-100 generations in the high- $\mathrm{CO}_{2}$ environments (Supplementary Figure S3). This partial reversal of the plastic response in lineages evolving in high- $\mathrm{CO}_{2}$ environments is extremely likely to be due to evolution. This is because first, it occurs while populations are still growing in the high- $\mathrm{CO}_{2}$ environment and, second, it is considerably slower than the reversal of the plastic response seen when we transfer SA or FA populations from 1000 atm $\mathrm{CO}_{2}$ back to $430 \mu$ atm $\mathrm{CO}_{2}$. There, the SA- or FA-evolved phenotype is re-established with 7-14 generations (Supplementary Figure S1A).

In the long-term, elevated $\mathrm{CO}_{2}$ and fluctuations in $\mathrm{CO}_{2}$ both drive evolution of phenotypes in marine phytoplankton and explain $\sim 30 \%$ and $\sim 60 \%$ of the variation in the evolved phenotypes, respectively (Figure 3). Lineages evolved in $\mathrm{FH}$ are different from those evolved in SH (ANOVA all traits, selection $\mathrm{CO}_{2}$ 


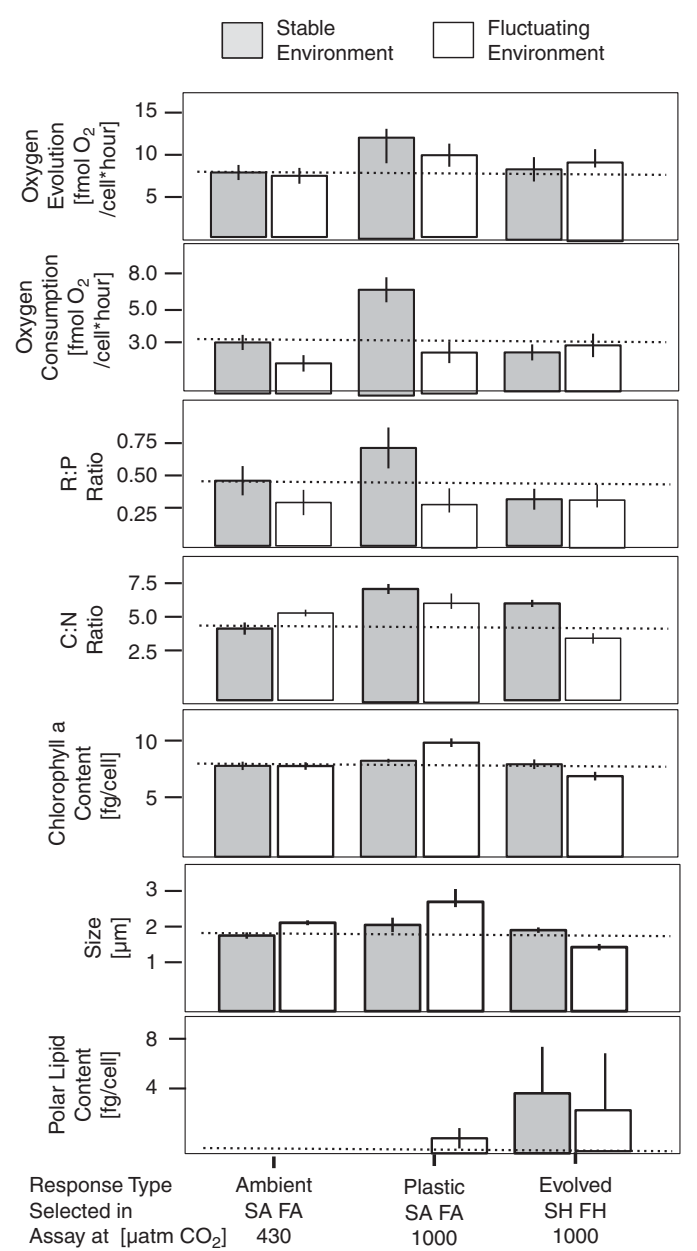

Figure 2 Ambient (left), plastic (middle) and evolved responses (right) to stable (grey) and fluctuating (white) $\mathrm{pCO}_{2}$ of phenotypic traits in Ostreococcus. Selection in $\mathrm{SH}$ and $\mathrm{FH}$ environments yields different phenotypes, which also differ from plastic response. As a guideline, the dashed line represents mean values of each trait for SA lineages assayed at $430 \mu \mathrm{atm} \mathrm{CO}_{2}$. Bars are means \pm 1 s.e. Post-hoc results are summarized in Supplementary Table S3. In the stable environment (grey), high $\mathrm{CO}_{2}$-evolved phenotypes differ from the ambient response with regards to oxygen evolution, oxygen consumption, R:P ratio, C:N ratio and lipid content. The plastic response of SA-evolved lineages differs from the evolved response (SH-evolved lineages) for oxygen evolution, oxygen consumption, R:P ratio, C:N ratio and lipid content. For lineages evolved in a fluctuating environment, there are significant differences between FA- and FH-evolved lineages in oxygen evolution, $\mathrm{C}: \mathrm{N}$ ratio, chlorophyll a content, size and polar lipid content. The plastic response of FA lineages is different from the evolved response (that is, FH lineages) for C:N ratio, chlorophyll a content, cell size and polar lipid content. Phenotypes of SH lineages are different from those measured in $\mathrm{FH}$ lineages for oxygen consumption, $\mathrm{C}: \mathrm{N}$ ratio chlorophyll a content and size. After evolution in $\mathrm{SH}$ or $\mathrm{FH}$, lineages from the stable environment are characterized by lower oxygen consumption rates, higher C:N ratios, higher chlorophyll content per cell volume and larger cells than lineages that had evolved in a fluctuating environment.

$(\mathrm{sco}) \times$ environmental fluctuation (ef), $\mathrm{F}_{1,118}=11.34$, $P<0.01$, Figure 2 and also Supplementary Table S3). For example, FH-evolved lineages respire more than $\mathrm{SH}$-evolved lineages do (post-hoc $P<0.05)$, have lower C:N ratios (post-hoc $P<0.01$ ) and are smaller with less chlorophyll a per cell than SH-evolved lineages (both post-hoc $P<0.01$ ). Oxygen evolution rates, respiration to photosynthesis ratio ( $\mathrm{R}: \mathrm{P}$ ratio) and lipid content are not significantly different overall, but there are significant differences on the level of the individual lineages for these traits (ANOVA, sco $\times$ ef, $F_{15,109}=77.43, \quad P<0.05$, Supplementary Figure S4). Overall, we cannot use $\mathrm{SH}$-evolved phenotypes to predict $\mathrm{FH}$-evolved ones (see Supplementary Figure S5). Below, we describe the SH- and FH-evolved phenotypes in detail and discuss the potential implications on marine food webs and carbon cycling.

Trait evolution and their implications for productivity and higher trophic levels. Oxygen evolution rates are higher than they are at ambient $\mathrm{CO}_{2}$ levels in both SH-evolved and FH-evolved linages (Figure 2), with rates of $9.07 \pm 0.14$ and $9.6 \pm 1.3 \mathrm{fmol}$ $\mathrm{O}_{2}$ per cell per hour, respectively. The average oxygen consumption rate after selection at $\mathrm{SH}$ is $3.2 \pm 0.2 \mathrm{fmol} \mathrm{O}_{2}$ per cell and $3.6 \pm 0.2 \mathrm{fmol} \mathrm{O}_{2}$ per cell per hour in FH. Mean R:P ratios are $0.35 \pm 0.2$ and $0.38 \pm 0.2$ for $\mathrm{SH}$ and $\mathrm{FH}$, respectively. Even though there is a general decrease in $\mathrm{R}: \mathrm{P}$ ratios in both $\mathrm{SH}$ - and FH-evolved lineages compared with the ancestral phenotype, there are large differences depending on the lineages' sampling origin (Figure 3 and Supplementary Figure S6, ANOVA RP ratio, sco $\times$ ef, $\left.\mathrm{F}_{1,122}=59.6, P<0.01\right)$.

C: $\mathrm{N}$ ratios in $\mathrm{SH}$-evolved lineages are at $7.5 \pm 0.15$ and at $5.3 \pm 0.3$ in FH-evolved lineages (Figure 2). Strikingly, this means that SH-evolved lineages evolve a 1.34-fold higher C:N ratio than SA-evolved lineages (post-hoc $P<0.01$ ), whereas $\mathrm{FH}$-evolved lineages have lower $\mathrm{C}: \mathrm{N}$ ratios than FA-evolved lineages (post-hoc $P<0.01$. C:N ratios in FA are 1.2-fold higher than in $\mathrm{FH}$ ). The decrease in C:N is particularly marked for Ostreococcus isolated in 'deep-sea' locations (Supplementary Figure S6, post-hoc $P<0.05$ ).

The average size and chlorophyll content of Ostreococcus cells also changes in response to $\mathrm{SH}$ and FH. In SH-evolved lineages, Ostreococcus from the surface and mid-depth locations are slightly larger in size with higher chlorophyll a content per cell than 'deep sea' ones (post-hoc $P<0.05$, Figure 3 and Supplementary Figure S6). On average, SHevolved cells are $2.19 \pm 0.14 \mu \mathrm{m}$ in size and contain $10.9 \pm 1.93 \mathrm{fg}$ chlorophyll a (Figure 2). FH-evolved cells are smaller and contain less chlorophyll a than FA-evolved cells (both post-hoc $P<0.01$, Figure 2), measuring $1.73 \pm 0.03 \mu \mathrm{m}$ and containing $9.49 \pm 0.2 \mathrm{fg}$ per cell. After evolution at $\mathrm{SH}$ and $\mathrm{FH}$, intracellular polar lipid content measured as Nile Red fluorescence increases in 6 out of 16 lineages, but no change in polar lipid content was found in the other lineages (Figure 2 and Supplementary Figures S4).

Differences in C:N ratio, cell size and lipid content between lineages evolved in stable and FH environments may affect trophic interactions 
80

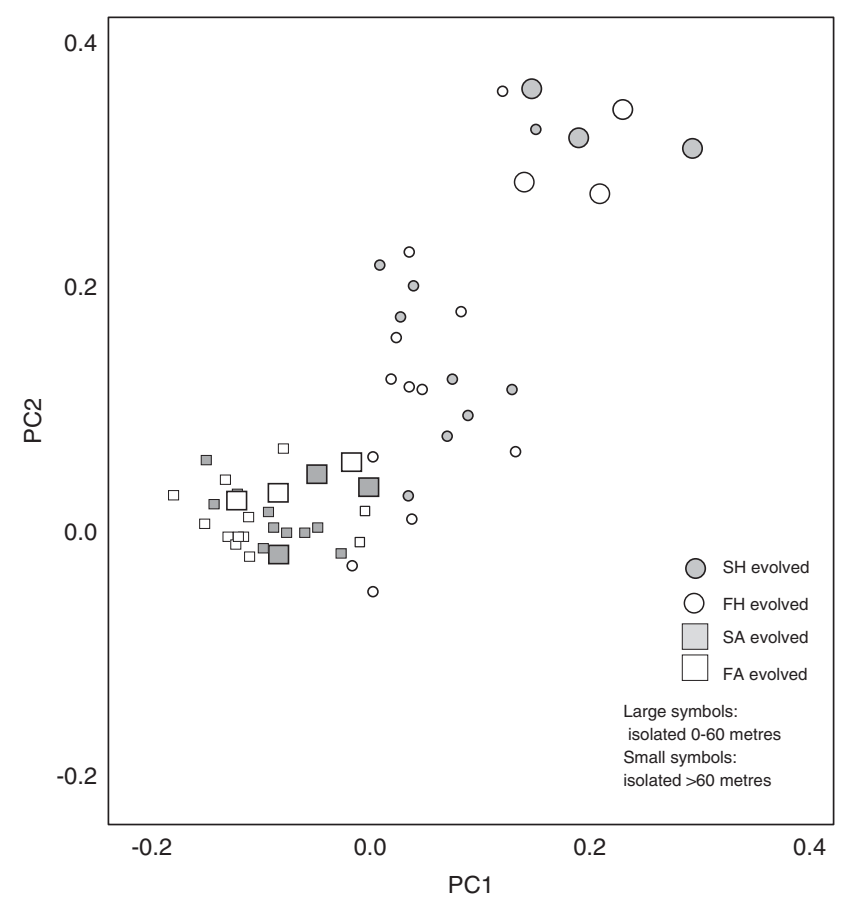

Figure 3 PCA showing that both environmental stability (PC1) and $\mathrm{CO}_{2}$ elevation (PC2) drive phenotypic evolution of lineages. Large symbols, lineages sampled from above 60-m depth; small symbols, lineages sampled from below 60-m depth; circles, evolved in high- $\mathrm{CO}_{2}$ environment; squares, evolved in ambient $\mathrm{CO}_{2}$ environment; grey, evolved in fluctuating environment; white, evolved in stable environment. See Supplementary Information for a color-coded version where each lineage is represented by a unique symbol (Supplementary Figure S7). Together, fluctuation and elevation of $\mathrm{pCO}_{2}$ explain $\sim 90 \%$ of the variance in evolved phenotypes and lineages (within $\mathrm{CO}_{2}$ treatments) cluster largely according to sampling depth.

and biogeochemical cycles. This is particularly the case when we also consider that frequencies of lineages within phytoplankton communities are expected to change. We have previously shown that lineages with larger plastic response to elevated $\mathrm{CO}_{2}$ will increase in frequency in the short term and also have a larger evolutionary response in the long term (Schaum and Collins, 2014). Although betweenlineage variance in growth rate is larger before evolution (0.36, see Schaum et al., 2013) than after evolution in $\mathrm{SH}(0.12)$ and $\mathrm{FH}$ (0.13), our findings show that $\mathrm{SH}$ - and FH-evolved lineages have evolved differently.

Ostreococcus evolved in high- $\mathrm{CO}_{2}$ environments show changes in growth rate, size and C:N ratio, indicating that future changes to productivity and carbon export by picoplankton are likely. Our data suggest that the magnitude of this change will vary locally, as there was substantial variation among lineages in some evolved traits (measured in this experiment and in Schaum and Collins, 2014), local variation in both $\mathrm{CO}_{2}$ levels and fluctuations in $\mathrm{CO}_{2}$ levels (Egleston et al., 2010), which will affect how natural selection acts.

Our study was done using many lineages of a single genus. However, differences in evolutionary responses to environmental change between species is also likely to drive changes in primary production and carbon export. For example, mesocosm studies suggest that non-calcifying picoplankton, such as Ostreococcus, may become more frequent in future oceans, as they are less adversely affected by elevated $\mathrm{CO}_{2}$ levels than calcifying phytoplankton (Riebesell et al., 2008; Scheinin et al., 2015). Calcifying phytoplankton (for example, coccolithophores) and non-calcyfying phytoplankton (for example, diatoms and green algae) belong to different functional groups (Falkowski et al., 1998) and have different roles in ecosystem functions and services, which means that the relationship between within-group evolution and ecosystem function is likely complex. For example, picoplankton communities of future oceans may be more productive than picoplankton communities in today's oceans, but the overall productivity and export of the mixed functional group assemblages might still be lower under $\mathrm{CO}_{2}$-enrichment scenarios that favor an increase in frequency in picoplankon. This is because picoplankton are smaller and sink more slowly than larger plankton. However, even small picoplankton do contribute to carbon export after ingestion by planktonic grazers, or when they become heavier through aggregation (Riebesell and Wolf-Gladrow, 1992).

Size, lipid content and C:N ratio are important aspects of food quality (Thomsen et al., 2013; Rossoll et al., 2012). Organisms that graze on Ostreococcus, mainly heterotrophic nanoflagellates (Christaki et al., 1999; Cuevas, 2006), are size selective and may not be physically able to ingest a food source if it doubles in size, or eat enough of a food source if it decreases substantially in size. Here, FH-evolved lineages were smaller than lineages evolved in the $\mathrm{SH}$ environment, with little variation between lineages. Several lineages also evolved phenotypes that stored more lipids at high $\mathrm{CO}_{2}$ than at ambient $\mathrm{CO}_{2}$, which may be part of a general response to elevated $\mathrm{CO}_{2}$, causing a shift from oxidative toward reductive pathways (Rokitta et al., 2012). Overall changes in fatty acid composition of marine plankton can lead to lowered reproductive success in zooplankton grazers (Rossoll et al., 2012). If selection imposed in the $\mathrm{FH} \mathrm{CO}_{2}$ environment informs us about selection imposed by global change in oceans, grazers will have to feed on smaller, nitrogen-deplete, lipid-rich cells, and thus will have to ingest more cells than under the present day conditions. If the overall phytoplankton biomass in some lineages decreases, grazers and filter feeders may not be able to fulfil their nutritional requirements, or, alternatively, changes in phytoplankton may drive a co-evolutionary response in grazers. As the plastic response of Ostreococcus to elevated $\mathrm{CO}_{2}$ is different from the evolutionary response, grazers, with longer generation times than phytoplankton, may have to cope with an increasingly variable food source. There are a number of evolutionary responses to changes in their food source that could occur in grazers. For example, grazers may use conservative or diversified bet-hedging strategies to 

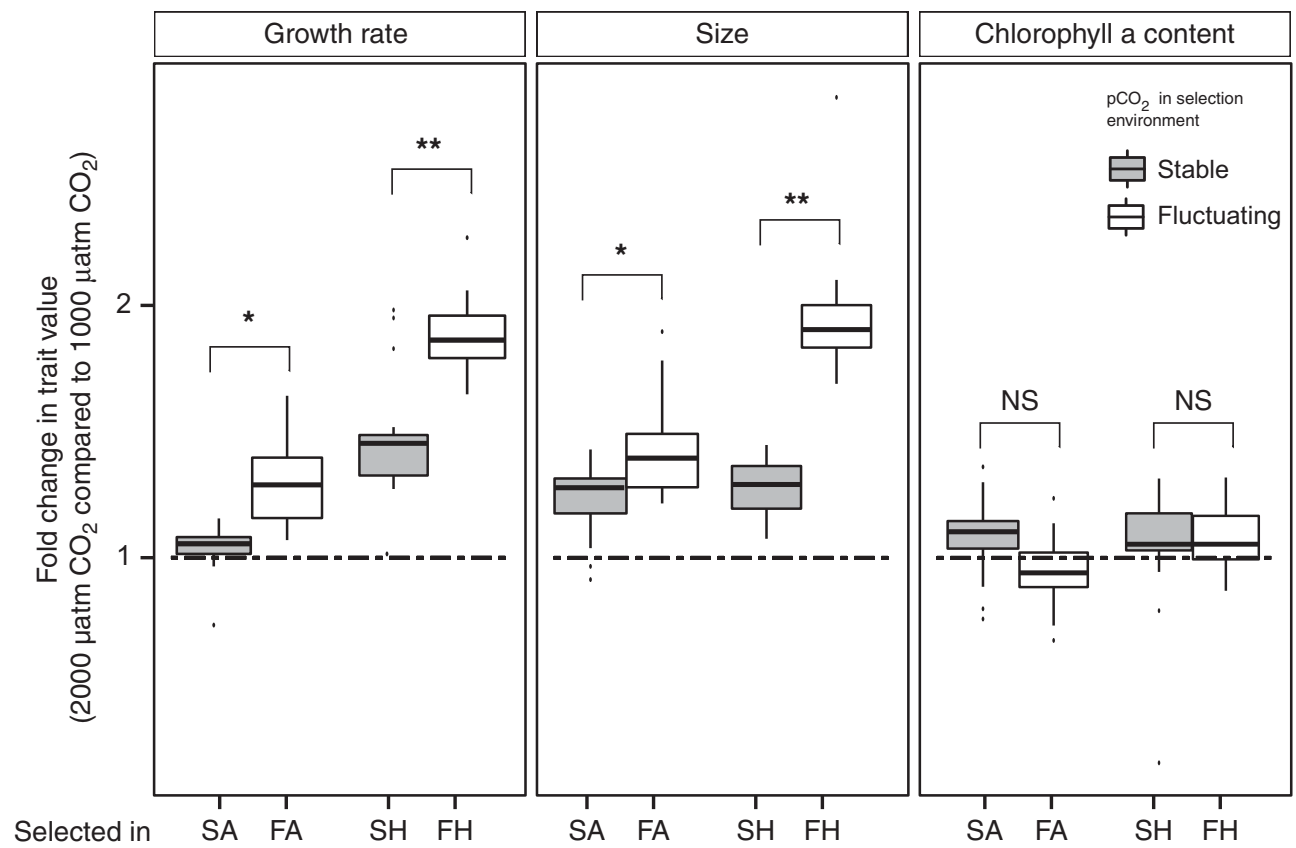

Figure 4 Selection history affects responses to different levels of elevated $\mathrm{pCO}_{2}$. Here, grey boxes represent pooled lineages from stable environments (SA and $\mathrm{SH}$ ) and white boxes represent pooled lineages from fluctuating environments (FA and FH). Boxplots are displayed with whiskers extending to the highest and the lowest values that are within 1 interquartile range (IQR) of lower/upper quartile. $n=3$ per lineage. NS, difference between lineages from stable and fluctuating selection regimes not significant; ${ }^{*} P<0.05$ and ${ }^{* *} P<0.01$, significant difference between lineages from stable or fluctuating environment, respectively. All values are displayed as fold change compared with the response to $1000 \mu \mathrm{atm}$ at $\mathrm{t400}$. This is the evolved response for $\mathrm{FH}$ and $\mathrm{SH}$, and the plastic response for SA and FA. Any values larger than 1 indicate that the response to $\mathrm{pCO}_{2} 2000 \mu \mathrm{atm}$ is stronger than the plastic or evolved (for SH and $\mathrm{FH}$ ) response to $\mathrm{pCO}_{2} 1000 \mu \mathrm{atm}$.

minimize fitness variance in the long term. Here the organisms either use the same, low-risk strategy (conservative) or invest in several strategies at once (diversified) (Beaumont et al., 2009; Ripa et al, 2010). In addition, grazers themselves may respond plastically to changes in their food source by switching the feeding mechanisms depending on the food source present in their habitat (Mariani et al., 2013). Finally, it is also possible that grazers will adjust to more variable food sources through evolution and adaptive tracking (that is, mutants arise and fix to fit the food source when it changes), or use a combination of the responses above.

Exposure to elevated fluctuating $\mathrm{CO}_{2}$ levels broadens the scope to react to further $\mathrm{CO}_{2}$ enrichment

A striking difference between lineages evolved in stable versus fluctuating environments in our experiment is how they respond to further increases in $\mathrm{pCO}_{2}$. Most $\mathrm{CO}_{2}$-enrichment experiments for marine phytoplankton use partial pressures of $\mathrm{CO}_{2}$ of around 700-1000 $\mu$ atm as their high- $\mathrm{CO}_{2}$ environment. As $\mathrm{CO}_{2}$ levels are expected to rise further and can also transiently rise above these levels today (IPCC report, 2007), it is important to investigate how evolution in moderately high- $\mathrm{CO}_{2}$ environments affects the response to shortterm exposure to even higher $\mathrm{CO}_{2}$ levels.

Both 1000 and $2000 \mu \mathrm{atm} \mathrm{CO}_{2}$ are considered to be 'high- $\mathrm{CO}_{2}$ conditions', but the ability of lineages to modulate their growth rates depends on the high- $\mathrm{CO}_{2}$ environment they experienced in their previous selection environment (ANOVA growth, response $2000 \mu \mathrm{atm} \times$ selection environment, $\left.\mathrm{F}_{3,105}=138.72, P<0.0001\right)$. Specifically, only lineages evolved in elevated or fluctuating $\mathrm{CO}_{2}$ environments grow differently at 1000 and 2000 ratm $\mathrm{CO}_{2}$, whereas SA-evolved lineages have the same growth rate in both 1000 and $2000 \mu$ atm $\mathrm{CO}_{2}$ (post-hoc $P=0.67$ for SA-evolved lineages, Figure 4). In FA-evolved lineages, which were transiently exposed to higher $\mathrm{CO}_{2}$ levels during evolution, growth rates are on average 1.22-fold higher at 2000 than at $1000 \mu \mathrm{atm} \mathrm{CO}_{2}$ (post-hoc $P<0.001$, Figure 4). In SH- and FH-evolved lineages, growth rates at $2000 \mu \mathrm{atm} \mathrm{CO}_{2}$ were 1.5- and 1.9-fold higher than at $1000 \mu \mathrm{atm} \mathrm{CO}_{2}$, respectively (post-hoc difference $\mu \mathrm{SH}$ and $\mathrm{FH}$ at $2000 \mu \mathrm{atm}<0.01)$. Changes in cell size in response to $2000 \mu \mathrm{atm} \mathrm{CO}_{2}$ were also larger in lineages from the $\mathrm{FH}$ environments than in lineages from the $\mathrm{SH}$ environment (ANOVA trait values, response $2000 \mu \mathrm{atm} \times$ selection environment, $\left.\mathrm{F}_{3,78}=2.89, P<0.05\right)$, whereas there was no significant difference in chlorophyll levels.

The differences in lineages evolved in stable and fluctuating environments show that evolving or maintaining the ability to distinguish between different high $\mathrm{CO}_{2}$ levels, even those outside the range of $\mathrm{CO}_{2}$ levels encountered in the past few hundred generations of evolution, only requires occasional exposure to high $\mathrm{CO}_{2}$. In our experiment, even the highest $\mathrm{CO}_{2}$ levels in the FA environment were lower than those in either $\mathrm{SH}$ or $\mathrm{FH}$, yet 
responses of FA to $2000 \mu$ atm were comparable to those of lineages evolved in the stable and $\mathrm{FH} \mathrm{CO}_{2}$ selection regimes. Although our experiment did not test this directly, we suggest that evolving in an environment where fluctuations are random has a role in lineages evolving the ability to specifically modulate their responses to further changes to the environment. Our reasoning is that an environment switching between two set levels of $\mathrm{CO}_{2}$ could select for generalists displaying the same phenotype across environments or a population composed of specialist subpopulations with distinct phenotypes in highand low- $\mathrm{CO}_{2}$ environments, but no specific evolution of the ability to deal with or distinguish between different high levels of $\mathrm{CO}_{2}$ (Kassen, 2002; Ketola et al., 2013). One possible reason that lineages evolved in fluctuating environments are able to respond by increasing growth at $2000 \mu \mathrm{atm} \mathrm{CO}_{2}$ is that they are not operating near limits set by oxidative damage (for example, see Dowling and Simmons, 2009) and are thus metabolically better equipped to deal with further perturbations to their environment. This is consistent with previous work showing the eventual evolution of reduced population growth rates but higher heat shock survival and better competitive abilities against novel conspecific competitors in Ostreococcus lineages evolving in high- $\mathrm{CO}_{2}$ environments (Schaum and Collins, 2014).

Regardless of the underlying cause, we show that evolving in fluctuating environments broadens the scope for using plastic responses in the face of continued environmental change (Figure 4). This is not limited to further increases in $\mathrm{pCO}_{2}$, but also extends to reduced $\mathrm{CO}_{2}$ levels: the correlated responses show that $\mathrm{FH}$-evolved lineages grew more rapidly in their ancestral environment $\left(430 \mu \mathrm{atm} \mathrm{CO}_{2}\right)$ than did the $\mathrm{SH}$-evolved lineages (Supplementary Figure S1A and B and details in Schaum and Collins, 2014).

These findings indicate that both the average environment and the stability of the environment during evolution affect how populations respond to subsequent environmental fluctuations, and that changes in the stability of marine environments will likely have a key role in driving evolutionary outcomes. Taken together, the differences between lineages evolved in stable and fluctuating environments show that selection experiments carried out under stable conditions will fail to detect key changes in phenotype associated with evolving in fluctuating environments, in particular as we cannot use SHevolved phenotypes to predict FH-evolved ones.

\section{Conclusions}

Phenotypic evolution in high- $\mathrm{CO}_{2}$ environments depends on both deviations from the mean $\mathrm{CO}_{2}$ level and the absolute $\mathrm{CO}_{2}$ levels, and this is consistent over several lineages of a species complex. This study shows that fluctuations in $\mathrm{CO}_{2}$, in addition to differences in average $\mathrm{CO}_{2}$, are likely to be important drivers of evolutionary change in green algae as $\mathrm{CO}_{2}$ levels rise. Although the evolutionary response to long-term $\mathrm{CO}_{2}$ enrichment is to partially revert the plastic (short term) response, persistent changes in cellular size and composition remain. This indicates that evolutionary responses to high and fluctuating $\mathrm{CO}_{2}$ can change the role of marine phytoplankton in food webs and nutrient cycles.

\section{Conflict of Interest}

The authors declare no conflict of interest.

\section{Acknowledgements}

The selection experiment and subsequent assays were conducted at the University of Edinburgh (UK). Intracellular stoichiometry was measured at the Alfred Wegener Institute Bremerhaven (Germany). The research was supported by a Royal Society (UK) University Research Fellowship (SC), by the European Research Council (ERC) under the European Community's Seventh Framework Programme (FP7/2007-2013), ERC grant agreement 205150 (BR) and a Scottish Universities Life Science Alliance scholarship (C-ES). We thank M Allen and ASSEMBLE (Association of European Marine Biology Laboratories), Roscoff, for providing the Ostreococcus lineages; S Rokitta, K-U Richter and U Richter for assistance in the laboratory at the AWI; M Waterfall (UoE) for assistance with flow cytometry; and JA Raven, A Millar, G Yvon-Durocher and A Buckling for providing feedback on the manuscript.

\section{Author contributions}

ES designed and performed the experiments, analysed data and wrote the manuscript. SC designed the experiments, analysed data, wrote the manuscript and supervised the laboratory work. BR supervised the laboratory work at the Alfred Wegener institute and contributed to the writing of the manuscript.

\section{References}

Beaumont HJE, Gallie J, Kost C, Ferguson G, Rainey PB. (2009). Experimental evolution of bet hedging. Nature 462: 90-93.

Beardall J, Raven JA. (2004). The potential effects of global climate change on microalgal photosynthesis, growth and ecology. Phycologia 43: 26-40.

Chevin LM, Gallet R, Gomulkiewicz R, Holt RD, Fellous S. (2013). Phenotypic plasticity in evolutionary rescue experiments. Proc $R$ Soc B 368: 20120089.

Christaki U, Jacquet S, Dolan JR, Vaulot D, Rassoulzadegan F. (1999). Growth and grazing on Prochlorococcus and Synechococcus by two marine ciliates. Limnol Oceangr 44: 52-61. 
Collins S. (2011). Many possible worlds: expanding the ecological scenarios in experimental evolution. Evol Biol 38: 3-14.

Collins S, Rost B, Rynearson TA. (2013). Evolutionary potential of marine phytoplankton under ocean acidification. Evol Appl 7: 140-155.

Courties C, Vaquer A, Troussellier M, Lautier J, Chrétiennot-Dinet MJ, Neveux J et al. (1994). Smallest eukaryotic organism. Nature 370: 255-255.

Crawfurd KJ, Raven JA, Wheeler GL, Baxter EJ, Joint I. (2011). The response of Thalassiosira pseudonana to long-term exposure to increased CO2 and decreased pH. PLoS One 6: e26695.

Cuevas LA. (2006). Nanoheterotroph grazing on bacteria and cyanobacteria in oxic and suboxic waters in coastal upwelling areas off northern Chile. J Plank Res 28: 385-397.

Dowling DK, Simmons LW. (2009). Reactive oxygen species as universal constraints in life- history evolution. Proc $R$ Soc B 276: 1737-1745.

Draghi JA, Whitlock MC. (2012). Phenotypic plasticity facilitates mutational variance, genetic variance, and evolvability along the major axis of environmental variation. Evolution 66: 2891-2902.

Egleston ES, Sabine CL, Morel FMM. (2010). Revelle revisited: buffer factors that quantify the response of ocean chemistry to changes in DIC and alkalinity. Global Biogeochem Cycles 24: GB1002.

Falkowski PG, Barber R, Smetacek V. (1998). Biogeochemical controls and feedbacks on ocean primary production. Science 281: 200-206.

Flynn KJ, Blackford JC, Baird ME, Raven JA, Clark DR, Beardall J et al. (2012). Changes in $\mathrm{pH}$ at the exterior surface of plankton with ocean acidification. Nat Clim Change 2: 510-513.

Ghalambor CK, Mckay JK, Carroll SP, Reznick DN. (2007). Adaptive versus non-adaptive phenotypic plasticity and the potential for contemporary adaptation in new environments. Funct Ecol 21: 394-407.

Gilbert JA, Field D, Huang Y, Edwards R, Li W, Gilna P et al. (2008). Detection of large numbers of novel sequences in the metatranscriptomes of complex marine microbial communities. PLoS One 3: e3042.

Guzmán HM, la Jara Valido de A, Duarte LC, Presmanes KF. (2009). Estimate by means of flow cytometry of variation in composition of fatty acids from Tetraselmis suecica in response to culture conditions. Aquacult Int 18: 189-199.

Holm-Hansen O, Riemann B. (1978). Chlorophyll a determination: improvements in methodology. Oikos 30: 438

IPCC 2007 Intergovernmental Panel on Climate Change (2007), Working Group I report 'The physical science basis'. Available at http://www.ipcc.ch/report/ar5/ wg1/.

Joint I, Doney SC, Karl DM. (2011). Will ocean acidification affect marine microbes? ISME J 5: 1-7.

la Jara de A, Mendoza H, Martel A, Molina C, Diaz R. (2003). Flow cytometric determination of lipid content in a marine dinoflagellate, Crypthecodinium cohnii. J Appl Physiol 15: 433-438.

Karve S, Daniel S, Chavhan Y, Anand A, Kharola SS, Dey S. (2014), E. coli populations in unpredictably fluctuating environments evolve to face novel stresses through enhanced efflux activity, bioRxiv, doi. http:// dx.doi.org/10.1101/011007.
Kassen R. (2002). The experimental evolution of specialists, generalists, and the maintenance of diversity. J Evol Biol 15: 173-190.

Ketola T, Mikonranta L, Zhang J, Saarinen K, Örmälä A-M, Friman V-P et al. (2013). Fluctuating temperature leads to evolution of thermal generalism and preadaptation to novel environments. Evolution 67: 2936-2944.

Li G, Wu Y, Gao KS. (2009). Effects of Typhoon Kaemi on coastal phytoplankton assemblages in the South China Sea, with special reference to the effects of solar UV radiation. J Geophys Res 114: G04029.

Lohbeck KT, Riebesell U, Reusch TBH. (2012). Adaptive evolution of a key phytoplankton species to ocean acidification. Nat Geosci 5: 346-351.

Mariani P, Andersen KH, Visser AW, Barton AD, Kiørboe T. (2013). Control of plankton seasonal succession by adaptive grazing. Limnol Oceanogr 58: 173-184.

Marie D, Simon N, Vaulot D. (2005). Phytoplankton cell counting by flow cytometry. In Algal Culturing Techniques. Vol 1 Elsevier: Oxford, UK. pp 253-267.

Petersen TW, Brent Harrison C, Horner DN, van den Engh G. (2012). Flow cytometric characterization of marine microbes. Methods 57: 350-358.

Pinheiro JC, Bates DM. (2000). Mixed-effects models in $S$ and S-PLUS. Statistics and Computing. Springer: New York. pp 146-174, 283-479.

Riebesell U, Wolf-Gladrow DA. (1992). The relationship between physical aggregation of phytoplankton and particle flux: a numerical model. Deep Sea Res $A$ Oceanogr Res Papers 39: 1085-1102.

Riebesell U, Bellerby RGJ, Grossart HP, Thingstad F. (2008). Mesocosm CO2 perturbation studies: from organism to community level. Biogeosciences 5: 1157-1164.

Ripa J, Olofsson H, Jonzen N. (2010). What is bethedging, really? Proc $R$ Soc $B$, (2010) 277: 1153-1154.

Rokitta SD, John U, Rost B. (2012). Ocean acidification affects redox-balance and ion-homeostasis in the life-cycle stages of Emiliania huxleyi. PLoS One 7: e52212.

Rossoll D, Bermúdez R, Hauss H, Schulz KG, Riebesell U, Sommer U et al. (2012)Ocean acidification-induced food quality deterioration constrains trophic transferPLoS One 7: e34737.

Schaum CE, Collins S. (2014). Plasticity predicts evolution in a marine alga. Proc Biol Sci 281: $20141486-20141486$.

Schaum E, Rost B, Millar AJ, Collins S. (2013). Variation in plastic responses of a globally distributed picoplankton species to ocean acidification. Nat Clim Change $\mathbf{3}$ : 298-302.

Scheinin M, Riebesell U, Rynearson T, Lohbeck K, Collins S. (2015). Experimental evolution gone wild. $J$ Soc Interface 12: 20150056. http://dx.doi.org/ 10.1098/rsif.2015.0056.

Schlüter L, Lohbeck KT, Gutowska MA, Gröger JP, Riebesell U, Reusch TBH. (2014). Adaptation of a globally important coccolithophore to ocean warming and acidification. Nat Clim Change 4: 1024-1030.

Subirana L, Pequin B, Michely S, Escande M-L, Meilland J, Derelle E et al. (2013). Morphology, genome plasticity, and phylogeny in the genus Ostreococcus. Ann Anat 164: 643-659.

Tatters AO, Schnetzer A, Fu F, Lie AYA, Caron DA, Hutchins DA. (2013). Short- versus long-term responses 
to changing $\mathrm{CO} 2$ in a coastal dinoflagellate bloom: implications for interspecific competitive interactions and community structure. Evolution 67: 1879-1891.

Thomsen J, Casties I, Pansch C, Körtzinger A, Melzner F. (2013). Food availability outweighs ocean acidification effects in juvenile Mytilus edulis: laboratory and field experiments. Glob Change Biol 19: 1017-1027.
West-Eberhard M. J. (2003). Developmental Plasticity and Evolution. Oxford University Press: New York.

Zhang Y, Klapper R, Lohbeck KT, Bach LT, Schulz KG, Reusch TBH et al. (2014). Between- and within-population variations in thermal reaction norms of the coccolithophore Emiliania huxleyi. Limnol Oceangr 59: 1570-1580.

Supplementary Information accompanies this paper on The ISME Journal website (http://www.nature.com/ismej) 